\title{
The Construction of a Web-Based Learning Platform from the Perspective of Computer Support for Collaborative Design
}

\author{
Hsu, Cheng Mei \\ Department of Visual Communication and Design \\ China University of Technology \\ Taipei City, Taiwan (R.O.C.)
}

\begin{abstract}
The purpose of this study is to construct a web-based learning platform of Computer Support for Collaborative Design (CSCD) based on theories related to a constructivist learning environment model, mind mapping and computer-supported collaborative learning. The platform conforms to the needs of design students and provides effective tools for interaction and collaborative learning by integrating the tools of mind mapping into a learning environment that utilizes CSCD, a computerassisted support system that can support and enhance group collaboration. The establishment of the CSCD learning platform represents a significant advance from the fixed functions and existing models of current online learning platforms and is the only learning platform in the world that focuses on learners in design departments. The platform is outstanding for its excellence, user-friendly functions, and innovative technology. In terms of funding, technical ability, human resources, organizational strategies, and risk analysis and evaluations, the learning platform is also worthy of expansion and implementation.
\end{abstract}

Keywords- computer support for collaborative design; computer support for collaborative learning; design education; mind-map; web-based learning platform.

\section{INTRODUCTION}

The advancement of information media and the convenience of the Internet have fostered the growth of webbased instruction, interactive functions, and resources available for learners to engage in interaction, learning, discussion, and access without time and geographic constraints. In design practice, the integration of computer technology has allowed designers to practice with consistency and innovation design approaches that were long believed to be possible only through the use of traditional tools or simulated hand-made physical objects, and ways in which humans communicate have been improved [20], [44]. Hence, web-based instruction is essential for design education.

However, because of how quickly departments have implemented network-based teaching, design departments fall short in comparison. The reasons for this delay include the many unique features of design education, such as difficulties with the design materials or works into digital formats [8], [22], [56], [61], [62], and the functions of current general webbased learning platforms are insufficient for teaching design, thus resulting in slow progress of web-based design instruction [10]. Based on the special knowledge and techniques of design, design students also possess unique learning styles and specialties, and they need to integrate related knowledge and coordinate professionals from different fields during the design process. For these reasons, the establishment of an individualized and adaptive web-based instructional platform that can enhance the effectiveness of design education remains a significant issue [11].

Creative thinking is one of the most important abilities in business and academic circles ([32], [52], [59]. Design students are highly sensitive to graphics and colors, and they are skilled at using visual-thinking models and the diffusion of images related to creative thinking methods to cultivate their creativity [30], [53], [55], [58]. Moreover, mind mapping is a learning method used to develop the potential of the left and right hemispheres of the human brain through graphic techniques. The design concept of mind mapping is associated with radiant thinking, which is a graphic type of organizational skill that incorporates graphics, colors, spaces, and imagination and effectively utilizes a whole-brain thinking method. The use of both graphics and text, in turn, enhances creativity, thereby completing the associative process of brainstorming [27], [49]. With advances in computer technology, computer-based mind mapping allows designers to create new concepts by freely linking concepts and integrating graphics, text, voice, video, and other multimedia through methods related to spatial and visual organization.

A designer must possess visual thinking capabilities, and mind mapping is a learning tool for graphic, visual, and spatial thinking. When applied to the creative thinking process in the early stages of a design, this tool may enhance a designer's creative thinking ability. To establish a web-based instructional platform that meets the user's needs and enhances learning effectiveness, the researcher proposed the CSCD platform, a design model based on design teachers' and students' needs for web-based instructional platform functions and learning tools. This model was developed by considering previously conducted research [63] applying the analytic hierarchy process (AHP) and by using learning theory as the basis for integrating and analyzing the design of the constructivist learning environment model, the Blackboard platform, the National Sun Yat-Sen Cyber University platform, and e-learning tools of 
technology companies for designing. Then, the researcher put forward the "Computer Support for Collaborative Design (CSCD) platform" design model based on the design department teachers' and students' needs for the web-based instruction platform functions and learning tools. Subsequently, the technical capabilities of many technology experts were integrated to establish a CSCD platform prototype, and modifications were conducted based on expert validity and user tests. After completing the CSCD platform, the experts and users assessed its usability and the overall design results through formative evaluations. The evaluation results show that the experts and users provided very positive feedback and believed that the platform not only possessed strengths lacking in general online learning platforms but also that the completion of the setup marked the beginning of a customized web-based learning platforms. The platform combines several web-based technologies and teaching resources and displays works through multimedia graphics and animation, with userfriendly and image-style characteristics that are useful for learners with an expertise in imaging.

\section{A. The Purposes of the Research}

The research purposes include the following: 1) to design and set up a teaching website with the constructivist learning environment model, computer-supported collaborative learning theory, and mind mapping-related theories that serve as the basis; 2) to design and set up a teaching website that aids in understanding the influence of the CSCD and collaborative mind mapping on design department students' learning attitudes, learning effectiveness, and creativity.

\section{THEORETICAL FRAMEWORK}

With the constructivist learning environment, mind mapping-related theories, and computer-supported collaborative learning as its bases, the CSCD learning platform setup in this study can be described in the following section.

\section{A. The Construction of the Constructivist Learning Environment Model}

Jonassen [23] proposed the constructivist learning environment (CLE) model (Figure 1) with six elements. Based on the design teaching, design purposes, design methods, and other characteristics and from the perspective of the constructivist learning environment design, the relationship between the model's application and design education is proposed as follows:

\section{1) The Six Components of the Constructivist Learning Environment Model}

\section{a) Problems/Cases/Projects}

The CLE drills on a problem or issue, which are poorly structured, the answers are uncertain, and they are real-life problems that elicit motivation to train the learner to attempt to resolve them, complete projects, and apply the results to reallife situations.

\section{a) Relevant Cases}

In the CLE, relevant cases are provided. Through the introduction of cases and the demonstration of model works, novices have the opportunity to observe and learn. Moreover, through case-based reasoning, necessary referential experiences and scaffolding aids are provided for the learner to understand and resolve problems [45].

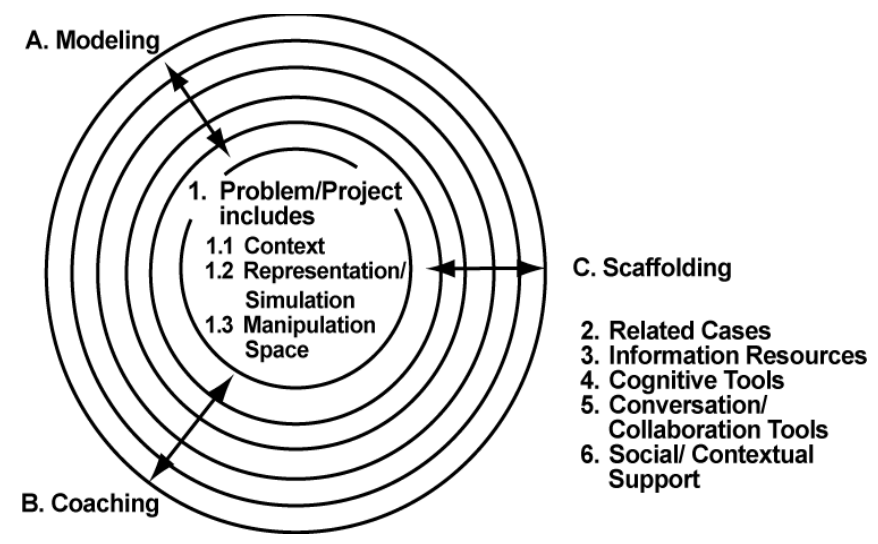

Figure 1. Constructivist Learning Environment Model (Source: Jonassen, 1999, p.218)

\section{b) Information Resources}

The CLE provides appropriate text files, pictures, sound resources, videos, animation, among other support information for building students' mental models and for forming a space for manipulating and thus solving problems.

\section{c) Cognitive (Knowledge Construction) Tools}

The CLE should provide cognitive (knowledge construction) tools such as databases, mind mapping, expert systems, and hypermedia to help solve problems and aid in extended thinking.

\section{d) Dialogue and Cooperation Tools}

The CLE should provide a variety of computer-mediated communication tools, such as various types of computer conferences, listservs, email, bulletin board, and NetNews services to support the learner in community cooperation, agreement, and decision-making, thus achieving a common goal (Scardamalia, 1994 cited from [23], p. 228;).

\section{e) Social or Situational Support}

The CLE's social or situational support includes completing and perfecting hardware, instruments, equipment, and other physical environments in the learning environment. Additionally, it includes the user's familiarity with the system tools of the learning platform and the operating method and the teachers' explanation or clarification of their opinions on students' questions.

2) The Three Teaching Strategies that Support the Implementation of a CLE

In a CLE, the teaching strategies should support the goals of the learning activities where appropriate. The implementation of the CLE is supported by three teaching strategies: modeling, guidance, and scaffolding aids.

\section{a) Modeling}

In a CLE, modeling provided by teachers can be divided into behavioral modeling and cognitive modeling; the former refers to the modeling of how activities are conducted, while the latter clearly expresses to students the need for reasoning during activities. 


\section{b) Guidance}

Guidance is provided when the learner seeks assistance. The guidance coach analyzes the learner's performance and provides feedback, reflections, suggestions, and skills for adjusting the learner's development, with emphasis on the learner's performance.

\section{c) Scaffolding Aid}

Unlike modeling and guidance, the scaffolding aid generally compensates for a learner's lack of prior knowledge. When a problem is encountered while executing a task, the teacher should employ a scaffolding-aided learning approach, such as adjusting the degree of operational difficulty, accommodating the learner's ability, restructuring the task to compensate for the lack of prior knowledge, or providing an alternative evaluation method to complete the task.

The three teaching strategies that support the CLE implementation coincide with the design teaching concept. In the design of teaching activities, the teacher's modeling and individual guidance enhance students' interest in learning through actual operation and the application of theories in practice [15].

\section{B. Mind Mapping}

\section{1) The Definition of Mind Mapping}

Mind mapping is a thinking-integration skill that is constantly linked to external concepts through an illustrated technique of association based on imagination. This technique transforms a central theme into a concrete one. Mind mapping associates objects through brainstorming to assist thinking and decision-making and to encourage problem solving by innovative means. By changing traditional logical and convergent thinking patterns through the use of lines, colors, text, numbers, symbols, graphics, keywords, and other methods of radiant thinking, the brain can freely radiate and associate, which encourages infinite creativity. Mind mapping not only characterizes the structure of knowledge but also aids in its absorption, compilation, and comprehension while enabling students to fully employ whole-brain creative thinking and problem solving ( [18], [21], [36], [37], [60].Mind mapping presents systematic knowledge through visual diagrams and text-based themes. The advantages of mind mapping include visualization, streamlining, integration, and focus, which all help the learner to fully apply brainstorming and free association through radiant thinking and composition methods. In education, mind mapping is not only an effective learning strategy but is also an essential tool for enhancing creativity. The computer-based mind-mapping technology uses a visualized thinking model, combines the Internet and multimedia (hypermedia) and thus allows users to arbitrarily organize and develop systematic knowledge, develop creativity, and express personal style. For these reasons, the technology greatly aids in teaching and learning.

\section{2) The Theoretical Foundation of Mind Mapping}

The process of mind mapping is compatible with the constructivist theory, meaningful learning, the radiant thinking model, and theories of whole-brain thinking.

a) The Constructivist Theory
In constructivism, knowledge is constructed, and the significance of the knowledge lies in the learner's integration of new ideas with past knowledge and experience, thus giving the phenomenon meaning and constructing his understanding about knowledge. This process of knowledge building is known as "meaningful learning". Initially, it is easy for the learner to assign meaning to things and phenomena, but with the accumulation of experience, the meanings assigned become more complex [24]. In summary, Constructivism emphasizes the following points: 1) the learning should be learner-centered, and knowledge is voluntarily obtained from the learner's past experiences, not directly from the teacher's instruction; 2) the learner combines new knowledge with old cognitive framework in a non-arbitrary manner; 3) learning cannot be accomplished by memorizing books; instead, the learner should integrate new knowledge with accumulated knowledge and assign it new meanings; 4) knowledge is complex and situational; therefore, the learner's understanding of knowledge should be characterized by complex knowledge [25].

\section{b) Meaningful Learning}

Meaningful learning refers to the combination of the learner's new knowledge and old cognitive framework in a nonarbitrary manner. Many scholars [1], [42] have suggested that learning is only effective if it is learner-oriented and if the learner understands the significance of the concepts gained. For learning to be meaningful, the teacher should first understand the learner's existing cognitive framework and then transfer new knowledge based on this cognitive structure, thereby enabling the learner to link the new and old cognitive structures.

\section{c) The Radiant Thinking Model}

Research has found that human brain waves do not travel in straight lines. Instead, the brain delivers messages in a radial manner. When a concept appears, the brain may generate a series of related ideas, and the relationship between the ideas and theme concepts is expressed in a radiant pattern. From each idea branched out (in text or images), more ideas can be generated. Mind mapping adopts such radiant thinking to simulate the brain's thinking patterns. Compared with traditional linear thinking, radiant thinking more effectively sparks creative ideas because it is characterized by lateral and vertical thinking, resulting in the free production of ideas, free association, and the generation of infinite creativity [3], [6],[33] , [35].

\section{d) The Whole-Brain Learning Model}

In the late 1960s, Professor Roger Sperry, from California, U.S.A., published his research results on the brain cortex, which showed that the left and right cortexes are responsible for different mental functions. The left brain specializes in learning-related functions, including linguistic and logical thinking; the right brain focuses on creative aspects, such as spatial perception, the Gestalt concept, color sensitivity, and range concepts [2], [6],[4], [7], [35], [46], [48]. However, the whole-brain thinking model involves the presentation of visually outlined views, messages turned into images, and memory associations, thus allowing the free display of thoughts and ideas and generating an integrated whole-brain 
operation, which further enhances the ability to learn and solve problems [6].

Mind mapping helps teachers to design meaningful learning environments. While a learning theory-based teaching environment encourages students to learn actively and enhances learning effectiveness, it also supports students' ability to solve complex problems and complete innovative tasks.

\section{Computer Support for Collaborative Design}

\section{1) The Meaning of Computer Support for Collaborative} Design

The CSCL applied to the field of design is known as the Computer Support for Collaborative Design (CSCD). Kvan [28] defines collaborative design as team members' negotiation, agreement, compromise, satisfying, and completion of stages in the design process and the achievement of goals that cannot be achieved individually. Kalay [26] suggested that a good design must be continuous and must integrate different specialties and shared knowledge. Lee [31] also found that collaborative design refers to the synchronized interaction, communication, and discussion of team members during the product development process. Moreover, to implement a design mission, the communication and collaborative tools must meet the needs of all the team members. CSCD means designing activities that support and strengthen teamwork through computer aids and support systems so that such activities can be integrated into computer technology-related applications, incorporate professional knowledge from different fields, share interdisciplinary expertise, and achieve perfect design results [47]. In practice, the designer must conduct complex communication and coordination among proprietors, material providers, and even partners and competitors in large projects [16]. Cross and Clayburn [14] also pointed out that in the design process, most problems are complex and difficult to solve, and groups are better able than individuals to acquire more information, which aids in the decision-making process. Teamwork with specialized personnel from other fields helps designers to complete projects. Hence, teamwork is essential in design [17], [64].

\section{2) The CSCD Applications}

Collaborative design has numerous benefits. Empirical studies have found that by incorporating the CSCL design in the planning of courses, the interactions among the learners via the computer platform could be enhanced, which contributed to learning effectiveness. The cross-functional team approach helps the designer to resolve design-related problems, shorten the time for product design and development, and reduce costs [9], [12], [54]. Teamwork is emphasized in practical design projects. The introduction of the CSCL in the design field and its further development into the CSCD enables team members to interact more frequently through collaborative discussions, helps to solve problems and enhances learning motivation and results. More importantly, with this kind of interaction, team members will elicit more creativity in one another. Thus, compared with other fields, the importance and value of the CSCD for design are critical. Tang, Lin and Chen [50] also found that concepts produced during the collaborative process can be applied to creative performance, and different knowledge and design experiences result in clearer and more complete design concepts, thereby producing better results. The division of tasks through teamwork can integrate the members' different skills and knowledge to enhance the diversity and integrity of design [43], [51], [57]. In particular, with the progress and popularization of network technologies, traditional face-toface and synchronous forms of communication, in view of their time and cost considerations, have gradually been supplanted by other forms of interaction and collaborative learning tools. These changes, while enabling students to engage in networked learning activities through constructive and collaborative learning methods, have reduced costs and enhanced communication and work efficiencies [13], [19], [23], [29].

The integration of network technology and teamwork has led to major changes in the design environment. The team members create interactive relationships through collaborative discussion, which helps to resolve problems, elicit creativity, and enhance learning motivation and results. Moreover, digital media have overcome the time and space constraints of traditional media, thus substantially improving production and operation techniques in the design industry. In other words, the support of computer technologies provides learners with useful resources and channels for collaborative learning so that learning can occur at any time and in any place. In addition, teachers' effectiveness can also be enhanced. The importance of design education is therefore clear.

\section{The Characteristics of Design Students}

Unlike other types of learners, design students possess characteristics such as graphics ability, creativity, and learning style. As Chen and You [12] stated, design departments greatly emphasize communication, discussion, and cooperation.

\section{1) The Personality Traits of Design Students}

Through in-depth interviews, Lin [34] found that design students possess the following characteristics: (1) they are more confident and demand perfection more than other students; (2) their interests in life are often related to what they have learned, such as computer graphics for design and painting, indicating their ability to integrate learning into life; (3) information gathering and sketching are the most common learning activities for finding inspiration and creative expression; (4) to enhance their professional capabilities, the students need to continually absorb information; (5) accumulated learning experiences provide design students with superior creative thinking, orderly analysis, and precise hand-eye coordination; (6) their preferred courses have stimulating designs, rather than recitation or theory-based instructional designs, to allow the expression of creativity.

\section{2) The Graphics Ability of Design Students}

Tseng [53] showed that compared with students from other departments, design students possess better creative thinking ability, specifically in dispersed graphics. Lee [30] also found that approximately $75 \%$ of college design students have a greater need for graphics data than for text data. Moreover, graphics, audio-visuals, and multimedia are important sources 
of inspiration and creativity for design students. In this study, computer-based mind mapping elicited students' creativity through constructive and organizational ideas and thus enhanced learning effectiveness. Wavering conducted research on high school students' logical and thinking abilities required for constructing linear diagrams. The results showed that the learners' operational and cognitive abilities were indeed associated with the learner's graphics capability.

\section{3) The Creativity of Design Students}

Design students possess not only an aesthetic sense but also the powers of observation, imagination, and creativity to develop design experiences and resolve design issues from different perspectives. Design students consider the ability to think creatively as most important, followed by the ability to engage in technical work [52]. Methods for cultivating design students' creativity should begin by improving teaching activities and learning environments. To foster students' creativity, teachers should design and implement innovative lessons based on students' characteristics [34].

Design students have greater sensitivity to images and colors, are skilled at visual thinking, know how to flexibly apply their learning, and are fond of dynamic learning methods and knowledge that can be applied to daily life. Hence, graphics and the teaching tools of text, voice, video, and multimedia should be applied to learning environment designs and teaching materials where appropriate. Additionally, open-ended creative activities should be designed, and learning aids and tools that meet the students' needs should be provided to enable design students to display their strengths, build their own knowledge structures, enhance their learning motivation, and develop good attitudes, thereby promoting academic achievement.

\section{REASERCH Method OF THE PRIMARY StUdy}

\section{A. The Research Framework}

This study is based on the ADDIE teaching design model, which consists of the following five processes: analysis, design, development, implementation, and evaluation underwent platform construction. First, the design teachers' and students' needs for the platform functions and learning tools on the platforms were analyzed; then, a CSCD learning platform model was designed. Next, feasible analysis was conducted, and the course content was planned to develop the CSCD platform. After integrating the information engineers' techniques, the CSCD platform was constructed. Finally, through expert opinions and user evaluations, the platform was corrected.

\section{B. The Research Procedures}

\section{1) The Demand Phase}

Based on previous studies analyzing theories and literatures related to web-based instructional platforms and domestic and foreign learning platform designs, this study constructed the functional design and integration framework of the web-based instructional platform. Then, the AHP hierarchical analysis was adopted to produce a questionnaire intended to reveal the design teachers' and students' (the main platform users) views on the platform functions and learning tools.

\section{2) The Design Phase}

In this study, the design model of the CSCD platform was established according to the users' needs. The CSCD model covers four functions: course information, teaching content, learning tools, and assistance (Q\&A and help). The model also includes seven learning tools: mind mapping, work display, electronic whiteboard, course discussion, virtual classroom, audio-video media, and relative links.

\section{3) The Develpoment Phase}

To understand the feasibility of the CSCD platform model setup, five engineers from information technology companies and school e-learning centres were interviewed in this study. Analysis and evaluation were conducted from the perspectives of costs, technical capacity, human resources, organizational strategies, possible risks, and prior setup-related experiences.

\section{4) The Setup Phase}

\section{a) The Construction of the Platform Prototype}

The results of the feasibility evaluation showed the possibility of the construction. Thus, numerous information engineers' techniques were integrated to construct the platform prototype.

\section{b) The Incorporation of Course Materials}

After constructing the platform prototype, the course materials were incorporated. With the "graduation topic" course as the example in this study, relevant teaching materials and references were provided by teachers with related experience and students who had taken the course.

\section{c) Expert Validity and User Testing}

After completing the CSCD platform prototype, the expert and user testings were conducted, and corrections were made based on the comments.

\section{5) The Evaluation Phase}

After correcting the CSCD platform, the experts and users then engaged in formative evaluation of the usability and overall design results of the platform.

\section{The Research Method}

\section{1) In-Depth Interviews}

After constructing the study's previous design and development phase and completing the construction and evaluation phases, the opinions of engineers' and school network managers' were collected through interviews.

\section{2) The Website Framework of the CSCD Platform}

The completed CSCD learning platform website framework is shown in Figure 2.

\section{FINDINGS AND DISCUSSION}

\section{A. Findings}

The CSCD platform functions are as follows:

\section{1) The Homepage}

After entering the platform, users register a new account, create a password on the right-hand side of the website and log in. The main page has nine course buttons. By clicking one of them, users are directed to the course profile page. The CSCD homepage is shown in Figure 3. 


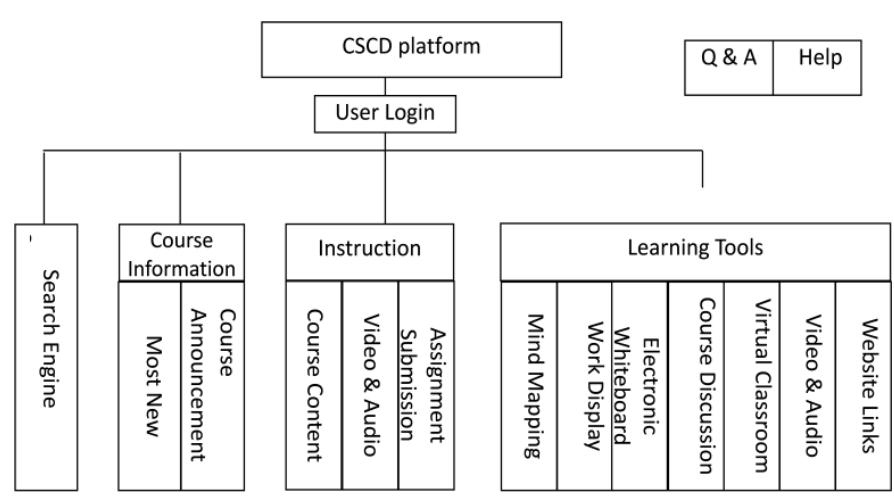

Figure 2. Website Framework of the CSCD Learning Platform

2) The Drop-Down Menu in the Top Middle Part of the Webpage

a) The Course information

The course information is divided into two parts: 1) News Updates. Users click this to enter the CSCD course discussion page. They should first read the instruction articles on the course discussion board to access the board; 2) Course Announcements. Users click this to enter and read the CSCD course-related news updates.

\section{b) The Teaching Content}

The items under this menu are managed by the course managers or teacher users and include course contents, audiovisual media, and assignment submissions. The maximum upload for assignment submissions is $20 \mathrm{M}$ per file, and the limit is subject to change as needed.

The capacity varies depending on the hard disc space available. The file extension formats of uploaded files are .zip, .rar, .pdf, .txt, .jpg, .tif, and .bmp, which are subject to change as needed, except ndex.htm, index.html, and index.php.

\section{c) The Student's Work}

This function in the menu classifies the students' work by topic. Users click on a work album to enter the browser screen and enjoy the various creative design projects.

\section{3) The Left Side of the Website}

\section{a) The Search Engine}

Users click the keyword to search pictures and data needed on the CSCD platform.

\section{b) The Display of Students' Work}

The students' work is automatically displayed randomly.

\section{c) The Counter}

The number of visitors to the CSCD platform is recorded.

\section{4) The Function Menu on the Right-Hand Side}

\section{a) The Course Menu}

The menu displays all nine courses provided on the CSCD platform: introduction to design, text style, digital editing and special effects, design creativity, composition, advertising design, photography, special topics design, and work collections.

\section{b) $Q \& A$}

This section introduces the menu functions and describes the various links while accessing the CSCD platform. Descriptions and solutions are also provided for various common operating problems.

c) Help

The help menu includes the CSCD course discussion boards, course announcements, and bulletin boards. New course information is constantly updated, and space is provided for users to engage in exchanges and discussions.

\section{d) The Website Homepage}

Users click this option to be directed to the homepage screen of the CSCD platform.

\section{5) The Learning Tool Area on the Right Side}

According to the needs of users, the CSCD platform provides learning tools such as mind mapping, work display, electronic whiteboard, course discussion, virtual classroom, audio-visual media, and links to websites. The functions of the various learning tools are as follows:

\section{a) Mind Mapping}

Students sketch mind mapping through the use of the program X-Mind and upload the sketches to the platform. The rotate, zoom-in and zoom-out, or full-screen functions can be used to view mind mapping. The mind-mapping display window is shown in Figure 4.

\section{b) The Work Display}

This platform provides space for displaying work, thereby allowing students to learn from each other. The platform is presented in images to better suit design students' characteristics and preferences. The students can preview works via thumbnail. Clicking on a picture will enlarge it for a better view. The students' work display window is shown in Figure 5.

\section{c) The Electronic Whiteboard}

Once the teacher removes the authorization limit, the students can freely sketch on the electronic whiteboard to explain their abstract concepts, which are considered very conducive to interaction. The teacher's explanations can also be viewed on the whiteboard, which produces excellent interaction results.

\section{d) Course Discussions}

This discussion board provides students with a forum for discussing their work and exchanging information outside of classes. In particular, because most design projects require teamwork, this interaction mechanism is critical.

\section{e) The Virtual Classroom}

Network learning environments with video conferencing allow students to feel as though they are in an actual classroom. Students should bring their own video cameras and recording devices. First-time users should first install the related equipment and programs. The Co-Life system allows 2-29 webcams to operate simultaneously (depending on the bandwidth and the devices being used). 


\section{f) Audiovisual Media}

Some audio and video courses, digital video editing or audio effects production courses, come with multimedia teaching materials and related resources. Course content presented via audiovisual media is more stimulating, and students can advance and rewind as they like, which enhances their learning interest and leads to more effective learning outcomes.

\section{g) Links to Websites}

Various multimedia information is provided, including photo gallery, illustration gallery, design gallery, audio and video gallery, and unclassified. Clicking the class directs the user to the corresponding website. These resources can better inspire designers.

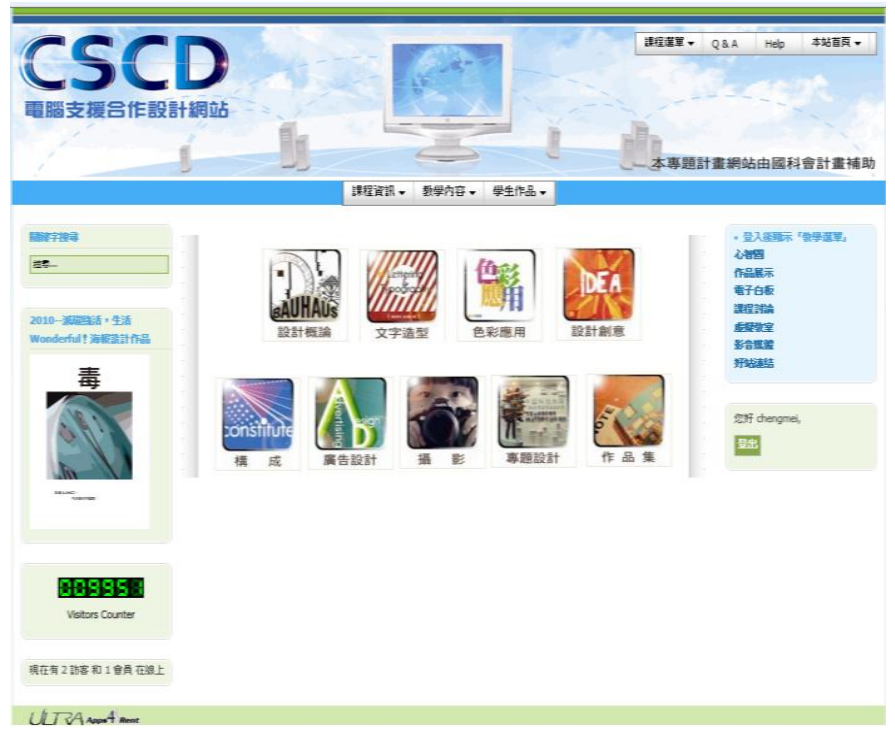

Figure 3. The CSCD Homepage

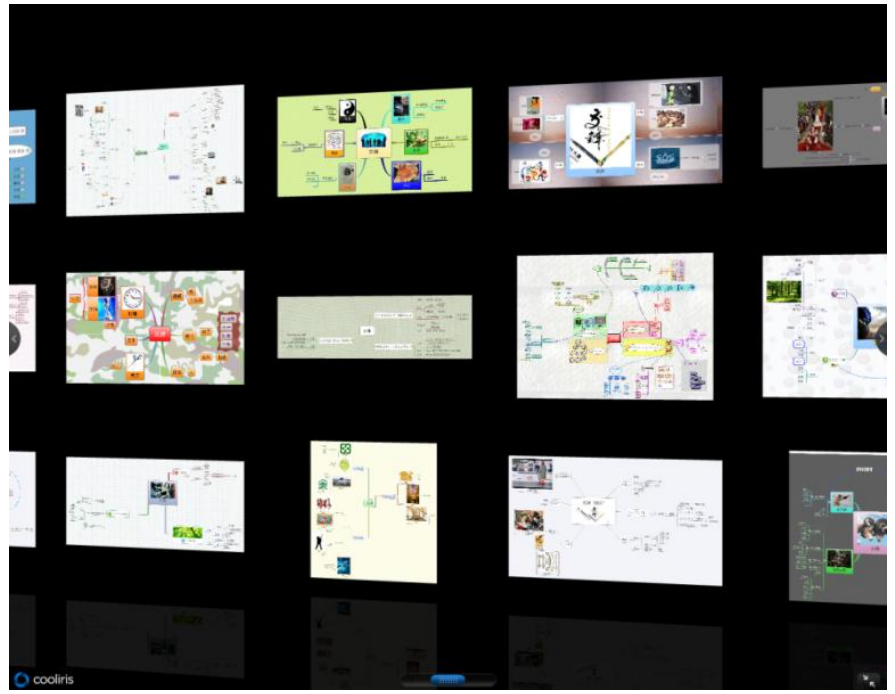

Figure 4. The Mind Mapping Display Window

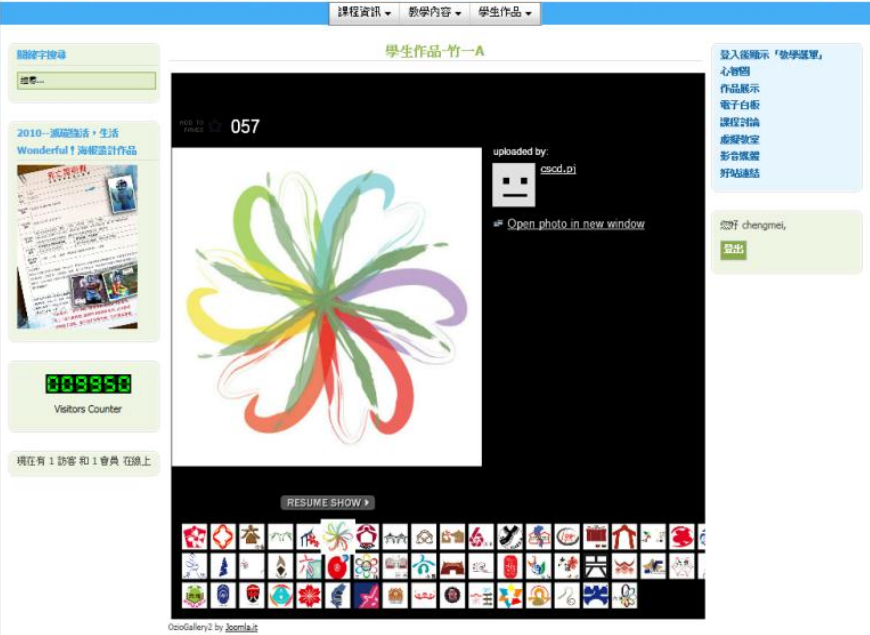

ULTANent mont

Figure 5. The Students’ Work Display Window

\section{B. Expert Opinions}

Interviews were conducted with the information engineers before and after setting up the CSCD platform. Their opinions of the platform setup are summarized as follows:

1) Related Supplementary Measures for Maintaining the CSCD Operations

Teaching and learning must be based on sound network environments and course-related information. Hence, the operation of the learning platform relies on the coordination of three aspects to smoothly carry out the platform functions:

(1) hardware resources; because the host is usually open 24 hours a day, it is normally deployed in an air-conditioned network-controlled room to be uniformly configured and managed by the school; (2) the management manpower on the back-end learning platform is the monitoring and management unit that supports network learning. The unit's role is to process quickly to ensure the normal operation of network learning and to assist platform users in delivering system and course announcements and consultations; (3) teaching assistant; the main task of this assistant is to support the teacher with instructional operations and to communicate with students regarding the various website functions. In the coordination and operation of these three aspects, the teaching assistant is more likely to support the course operation through searches and training, while the procurement of the hardware host (including the placement of the equipment, the power supply, the network cable configuration, the operating system installation, and related software program settings and modifications) and the management of human resources require further budget and other considerations.

\section{2) The Estimation of the CSCD Platform Setup Costs}

The platform setup costs primarily include the software and hardware equipment and the staff. 
The software and hardware equipment costs include the operating system and database software authorization fees and the budget for the software program of the learning platform management system. For the construction of the CSCD course functions and related technologies, a free content management system, the CMS Joomla website construction program, was used. Additionally, resources from the free database MySQL were adopted. To allow open source organizations to engage in development and support, Joomla applied various websites and progressive new technologies to enhance the responsiveness and performance of the websites. Furthermore, thousands of different website applications from around the globe, such as add-ons, graphic design and scenery developments, rapid deployment resources, and free and powerful extensions are performance strengths of the platform.

3) The Assessment of the Overall Technical Capacity of the CSCD Platform

First, with regard to the platform technology for constructing the CSCD platform, the operating system version of the web-based instructional environment as a whole should first be determined. Second, the various network and course function programs needed to set up the website are installed. Third, the various parameter settings are adjusted and modified. Fourth, art templates that match the visual style of the course program are edited and drawn. To maintain the normal operation of the platform, the host status should be regularly checked and maintained, and the course backup data should be downloaded.

\section{4) The Construction of the Human Resource Assessment of the CSCD Platform}

In addition to the school network managers, a teaching assistant is required to help students solve problems related to webpage browsing or platform use. The assistant also download assignments, edits course announcements and notices, contacts students, responds to the various discussions, explains the teacher-student contacts, and sends user comments, system problems and status updates to the system manager. These duties make the teaching assistant an important communication bridge between the system and the class.

\section{5) The Assessment of the Organizational Strategies on the CSCD Platform Setup}

The contribution level of the CSCD can be analyzed in two categories:

(1) platform usage, user satisfaction, and the ease of the platform operation; can the platform compensate for the inadequacies of classroom teaching? If the conducting of classes, teacher-student interactions, assignment assessments, and other teaching items can be fully applied to ensure CSCD performance, and the system can also review and modify the course implementation where appropriate, the CSCD setup will serve as a good model for similar implementations in the future, and the e-learning effectiveness of schools will also be enhanced; (2) analysis of the operating costs shows that the CSCD platform was constructed on the premises of low cost and high effectiveness, which will encourage the introduction of more courses and gradually increase the use of such courses. For example, there can be more synchronized online courses, more courses with simultaneous online access, and more online course activities can be used to observe the development of teaching.

6) The Assessment of Risks in the CSCD Platform Setup

In terms of a school's implementation of e-learning, the risks involved with this site are relatively low because of the minimal equipment and low system setup costs as well as the high expandability of the course functions. To maintain the smooth operation of the platform, the network technologies and related system developments should include periodic testing and updates.

7) The Assessment of the Innovative Technologies of the Learning Tools on the CSCD Platform

a) The Setup

The seven main learning tools of the web-based instructional platform (CSCD platform) include mind mapping, work display, electronic whiteboard, course discussion, virtual classroom, audio-visual media, and links to websites.

\section{b) The Mind-Mapping Tools: Ozio Gallery 2: Cooliris}

\section{Components}

The course options were originally designed for connecting to the Xmind website for online functional uses, but due to many online user authorizations and nonsynchronized teaching considerations, the options were changed to the Joomla components Ozio Gallery: Ozio Cooliris skin menu functions, and the students' mind-mapping operating files were used as a display. The mind-mapping work samples are displayed through the component functions. Clicks visually emphasize the dynamic results, or they can be watched on the full screen.

\section{c) The Work Display Tools: Flickr SliderShow Components}

The work display function is one of the website's most characteristic features. In terms of the website's course design attributes, related assignments and work displays are provided. Hence, in consideration of the website's file upload management and performance, the Flickr SliderShow components were adopted. With these components, including the storage spaces and application features provided on the Flickr website, intervals can be placed seconds apart, and file displays can be selected.

The visual output is stimulating and quick, while the click responses are sound. In addition to the static picture files in the website's design category, there are also mp3 files of multimedia sources and e-books that undergo audiovisual editing. Through the component functions, these options are directly available for listening on the website.

\section{d) The Electronic Whiteboard Tools: the Website Co- Life System}

The electronic whiteboard connects to the Co-Life audiovisual conferencing system. The system was developed by the National Centre for High-Performance Computing (NCHC) and can synchronize with the electronic whiteboard, the desktop, text, and other instant messages, and it can provide a remote common processing platform during the project plan development period. The system is an essential tool for a virtual team. 


\section{e) The Course Discussion Board Tools: the Component} Version Kunena Forum

The application of the discussion board comes in multiple usage operations, examples of which include the latest news, course announcements, and course information that uses the discussion board functions. With the privacy protection function, some discussion boards authorize only the teachers and students to use them by logging in, at which point they can participate in presentations and interactive discussions.

\section{f) The Virtual Classroom Tools: the Website Co-Life} System

The virtual classroom combines the Co-Life online conferencing system functions of the NCHC. Users should bring their own camera video communication devices, and first-time users must install the related equipment and programs. The Co-Life online conferencing system will also automatically detect and install the relevant software needed for the environment. The current computer automated functions, coupled with devices such as the USB, have been successfully completed for installation and use. The microphone audio input devices, however, can be divided into the sound card and the webcam. Users can decide which sound input to adopt for voice recording and play. In principle, with the academic network transmission conditions and the ADSL environment, the Co-Life online conferencing system is used for synchronized teaching in online conferencing, thereby achieving smooth two-way audiovisual communication quality. However, for users with lower network bandwidths, systems of this type may result in connection problems or poor video quality.

\section{g) The Audiovisual Media Tools}

The audiovisual media tools adopt the following Joomla expansion component: the Expose Flash Gallery 4.6.3 Alpha3c module, which can be classified or edited and is a powerful function for photographs and audiovisual displays.

\section{h) The Tools for Links to Websites}

The links to websites feature adopts the built-in components of the Joomla system: the version of the webpage link and classification lists will show all the lists for the webpage link classifications, which are managed by the background links for adding and editing.

\section{8) The Superiority of the CSCD Platform}

This website adopts the world-renowned Content Management System (CMS) Joomla website program setup, which features three advantages: (1) among the Joomla system expansion components, the multimedia graphics and animation performance are outstanding. These components not only display smooth and beautiful foreground results but also allow detailed adjustments of the background management functions, such as file uploading and parameter setting. When constructing and setting up website programs for various course tasks, the foreground and background performance and the operation of management-related configurations should be taken into consideration because these functions depend on the strengths and weaknesses of the website service program design, adjustments and optimized modifications of the relevant parameters to enable successful links to websites and normal launches. When designers consider setting up the Joomla version of the Content Management System, they should also consider numerous relevant support component functions, the technical community usage, and other related issues, as well as whether these functions meet the website requirements. From installing the host operating system to setting up the host system database and related components for convenient operating performance, the advantages of the CMS system for the course website are clear; (2) Joomla applies a wide range of new technologies that contribute to website progress, such as website caching technology, and can enhance responsiveness and performance of the website. Thousands of web-based add-ons and graphic design sets from around the world have been developed with this system as the basis. The expansion components with the features of quick setup, free resources, and powerful functions contribute to the website's outstanding performance; (3) when updates for the various essential component versions are available, the component version-related information can be quickly understood, and component function updates can be considered and selected.

The website combines various web-based technology and teaching resources, such as placing a large number of photographs and student image files on Flickr to save the website storage space and upload time. Additionally, the CMS system management function provides rapid and convenient browsing, and through classification links and overviews, the various themes are distinguished and presented. Furthermore, online submissions of work files, class announcements, and problem discussions can be directly conducted on this website. All the teaching resources and functions available on this website can be accessed only when teachers and students log in through their accounts and passwords, except for special authorizations for announcements and related course information. This feature thus protects information and allows convenient use. In addition, the recommended links on this website are mostly cited from the CC information network created by the Ministry of Education. Unless otherwise specified, the website contents are all labeled in CC names to promote the $\mathrm{CC}$ creation concept of network resource sharing.

\section{RECOMMENDATIONS}

\section{A. The Promotion of the CSCD Learning Platform}

The CSCD learning platform was completed based on the findings of this study, and the teaching theories include many network learning environment components that meet teaching requirements, thus offering a new opportunity for networking design teaching. In recent years, the Ministry of Education has actively promoted high-quality e-learning content applications [38], [39], [40], [41] to improve the breadth and depth of information network education in our country, thus providing a favorable social environment for implementing a "network design academy." Moreover, with the richer and more mature technologies and experiences of local companies' web-based instructional platform setups, sound external conditions for these setups have been provided. With the support of the above environments and conditions, the implementation of the "network design academy" model should be feasible. In this study, the environment of design network learning serves as 
the starting point for promoting the web-based design instruction, and it is hoped that this model will receive valuable feedback and encourage other professionals to join the R\&D, thereby achieving the goal of implementing the web-based design instruction.

\section{B. Making Good Use of the Network Technology and Multimedia Features in Teaching Design}

To strengthen the learners' intrinsic cognitive processes and enhance learning results, the design teaching network should make good use of the flexibility of the technology and the multimedia features when engaging teaching material content and learning activity designs. For example, problemsolving strategies and online questions are techniques used to continually test learning effectiveness and produce the power of urge, and these techniques provide onsite video recording of visitation and speech activities, which enhance the students' learning motivation and understanding of the content. Relevant videos and case files may also be provided for students to download, thus achieving the goal of active learning. In addition, the convenience of the network interactions also facilitates collaborative learning and online discussion, thereby achieving the goals of the CSCD.

\section{Establishing Responsible Units and Training Professionals to Develop Web-Based Design Instruction}

Currently, network learning programs are mostly promoted by school units (such as computing centers) or teaching development centers funded through program subsidies (such as the Teaching Excellence Program). Due to restrictions on funding and subsidies, problems related to network learning platforms cannot be effectively improved, and better platforms cannot be researched and developed. Therefore, it is suggested that schools establish responsible units to promote web-based design instruction, including the design of web-based teaching materials, the arrangement of web-based instruction activities, the design of network learning tools and interfaces, and other teaching resources with the assistance of professionals and administrative units (such as computing centers) in schools to construct high-quality web-based instructional environments.

\section{Promoting Mutual Growth and Complementarities between Academia and Industry through Industry- University Cooperation}

Numerous domestic universities have developed their own teaching materials and web-based learning platforms, but few have successfully applied them to industry settings. Because design departments have special requirements for learning tools and hardware for the web-based instructional platform, the software, hardware and $\mathrm{R} \& \mathrm{D}$ expenditures of design departments are much higher than those of other departments. Hence, for future platform setups, mutual cooperation between academia and industry should be adopted to obtain funding assistance, fully engage the different professions, construct an attractive platform with substantial teaching results, and meet users' needs. In addition, it is suggested that academia/university cooperation be adopted in the future to share research results and relevant innovative applications and concepts with the industry, thereby continuing to develop competitive products to be marketed.

\section{IMPLICATIONS}

\section{A. The Planning of the Overall Learning Environment}

This study started from the learning environment; through the web-based instructional platform, students' network learning motivation and performance can be enhanced. However, even with an appropriate web-based instructional platform that meets the requirements, there is no guarantee that the expected and ideal goal will be accomplished. Planning of the overall learning environment, including the coordination of teachers, course content designs, teaching activity designs, and comprehensive learning assessment methods that complement one another are required to achieve maximum network learning performance.

\section{B. The Selection of Appropriate Courses to Implement Network Teaching}

Although this study advocates design teaching and the implementation of networking, it is emphasized that network learning is not applicable to all design courses. For instance, traditional technical courses, including physical operation and other diverse contents, cannot and inappropriately be completely replaced by the web-based instruction. However, web-based instruction will have value for certain courses, such as digital technology classes (e.g., webpage production) and creative thinking classes (e.g., design creativity and creativity development) if the courses can be adapted to implement network teaching or serve as a learning aid with the help of advanced technology, network convenience, and effective learning tools. In other words, in design education, appropriate courses can be selected to implement network teaching and maximize the teaching value.

\section{Expanding the Platform Functions and Tool Applications within the Scope of Design Teaching}

Hindered by current web-based learning platforms that provide only general features, the network ranges and function-related applications of design teachers are focused mostly on discussion boards, data transmission, and assignment submissions, while other functions are rarely used. The CSCD platform constructed in this study provides mind mapping, work display, electronic whiteboards, and other learning tools, which are very helpful for web-based design instruction. Therefore, the researchers hope that the relevant design education units understand the value and uses of design teaching, that platform functions will be expanded, and that the relevant tools will be applied to the scope of design teaching to enhance the performance of assisted teaching.

\section{ACKNOWLEDGMENT}

This article adopted part of the research results of the 2009 National Science Council Research Projects (Project Number: NSC 99-2410-H-163 -004). We sincerely appreciate the funding of the government.

\section{REFERENCES}

[1] Ausubel, D. P., Novak, J. D., \& Hanesian, H. (1978). Educational psychology: A cognitive view (2nd ed.). New York: John Wiley \& Sons.

[2] Buzan, T. (2000). The mind map book. London: BBC.

[3] Buzan, T. (2005). Mind maps at work: How to be the best at your job and still have time to play. New York: Plume. 
[4] Buzan, T. (2007). Buzan center. Retrieved December 7, 2009, from http://mind-map.com

[5] Buzan, T. (2007). The speed reading book. (Mickey, S., \& Chen S.-Y. Trans.). Taipei: Yale International Cultural. (Original work published 2003).

[6] Buzan, T., \& Buzan, B. (2007). The Mind Map Book. (Mickey ,S. Trans.). Taipei: Yale International Culture Publishing Co., Ltd. (Original work published 1993).

[7] Colin, R. (2004). Accelerated learning for the $21^{\text {th }}$ century. (Pao-Lo Tai, Trans.). Taipei: Classic Communications Co. (Original work published 1997).

[8] Chang, M. -M. (2001). A study on the business strategy and the CFs of e-learning Web sites. Unpublished master thesis, National Changhua University of Education Institute of Business Education, Changhua, Taiwan.

[9] Chen, I. -W. (2004). The influence of designers' cognition styles on their team communication and problem-solving. Unpublished master thesis, Tatung University Graduate School of Industrial Design, Taipei, Taiwan.

[10] Chen, W. -Z., \& You, M. -L. (2001a). Internet mediated design course: The pilot study on IMDC model. The Journal of Design Research, 2, 109-115. Retrieved December 14, 2011, from http://thinkdesign.cgu.edu.tw/File_uploads/wenzhi/2001_CID6.pdf

[11] Chen, W. -Z., \& You, M. -L. (2001b). On application of internet in design education. Industrial Design, 29(2), 105-110. Retrieved December 14, 2011, from http://thinkdesign.cgu.edu.tw/File_uploads/wenzhi/2001_MIT.pdf

[12] Chen, W. -Z., \& You, M. -L. (2001c). On application of internet in design education. Paper presented at the meeting of the $16^{\text {th }}$ National Technical and Vocational Education Seminar, Hualien, Taiwan. Retrieved June 3, 2007, from http://thinkdesign.cgu.edu.tw/File_uploads/wenzhi/2001_TVE_16.pdf

[13] Chen, Y. -C., \& Huang, H. -H. (2001). An analysis of the interactive process of network collaborative learning and the role of the learner - the "teaching system design" e-course case study. Paper presented at the meeting of 2001 The International Seminar on Information Literacy and Lifelong Learning, Taichung, Taiwan.

[14] Cross, N., \& Clayburn-Cross, A. (1996). Observations of teamwork and social processes in design. In Cross N., Christiaans H. \& Dorst K. (Eds.), Analyzing design activity (pp. 291-317). New York: John Wiley and Sons.

[15] Curriculum Research and Development Center for Commerce Education (2001). Curriculum Final Report/ Final report on the design field. Retrieved December 22, 2011, from http://bcc.yuntech.edu.tw/TVEC/貫課程期末報告/設計群期末報告.pdf

[16] Department of Interior Design, Tainan university of technology (2010). Future prospects of the Department of Interior Design. Retrieved December 7, 2011, from http://203.68.182.102/idtut2/index.php?option=com_content\&task=view \&id $=17 \&$ Itemid $=32$

[17] Dorta, T., Lesage, A., \& Pérez, E. (2008). Point and Sketch: Collaboration in the hybrid ideation space, in C Bastien \& N Carbonell (eds), IHM 2008, ACM Interaction humain machine: 20 ans d'interaction homme-machine francophone: De l'interaction à la fusion entre l'humain et la technologie, Association for Computing Machinery (ACM), Metz, pp. 129-136.

[18] Features-Xmind (2010). Mind mapping and storming. Retrieved December 7, 2010, from http://www.xmind.net/pro/features

[19] Geer, I. W., Brey, J. A., Weinbeck, R.S., Moran, J. M., Ficek, M. M., Hopkins, E. J., \& Blair, B. A. (2000). Online weather studies: An introductory college level distance-learning course. American Meteorological Society, 9th Symposium on Education, AMS, Long Beach, CA, 144-147.

[20] Haymaker, J., Keel, P., Ackermann, E., \& Porter, W. (2000). Filter mediated design: Generating coherence in collaborative design, Design Studies, 21(2), 205-220.

[21] Hobin, E., \& Anderson, A. (2008). Middle-school students' concepts of health in Ontario and the British Virgin Islands and the implications for school health education. Physical \& Health Education Journal, 74(2), 16-22.

[22] Hsu, C. -M., \& Yen, J. (2006). The perspective analysis of the design teachers to the digitalized design courses -An application of WinMAX. The Journal of Design Research, 6, 189-199.

[23] Jonassen, D. H. (1999). Designing constructivist leaning environment. In C. M. Reigeluth (Ed.), Instructional design theories and models: A new paradigm of instructional theory (pp. 215-239). Mahwah, NJ: Lawrence Erlbaum Associates.

[24] Jonassen, D. H. (2000a). Jonassen's class notes, November 15, 2000.

[25] Jonassen, D. H. (Ed.) (2000b). Computer as mindtools for schools: Engaging critical thinking. Upper Saddle River, NJ: Prentice-Hall.

[26] Kalay, Y. E. (1999) The future of CAAD: From computer-aided design to computer-aided collaboration. In Augenbore, G. \& Eastman, C. (Ed.), Proceedings of the CAAD Futures' 99, Kluwer Academic, 13 -30.

[27] Karen Bromley, Linda Irwin-DeVitis, \& Marcia Modlo (2005). Graphic organizers. (Hsin-Jung Lee, Trans.). Taipei: Yuan-Liou. (Original work published 1995).

[28] Kvan, T. (2000). Collaborative design: what is it? Automation in Construction, 9, 409-415.

[29] Kwon, E. S. (2004). A new constructivist learning theory for web-based design learning with its implementation and interpretation for design education. Unpublished doctoral dissertation, Ohio State University, Ohio

[30] Lee, E. (2000). The study of information-seeking behavior: A case of the students of the design college of shih chien university. Unpublished master thesis, Tamkang University, Institute of Information and Library, Taipei, Taiwan.

[31] Lee, L. -C. (2004). The concept and characteristics of collaborative design (I). Retrieved December 7, 2011, from http://webcache.googleusercontent.com/search?q=cache:ZpRO156EjaEJ :www.boco.com.tw/newsdetail.aspx\%3Fbid\%3DB20070117002924+\% $\mathrm{E} 6 \% 9 \mathrm{D} \% 8 \mathrm{E} \% \mathrm{E} 4 \% \mathrm{BE} \% 86 \% \mathrm{E} 6 \% 98 \% \mathrm{~A} 5+2004+\% \mathrm{E} 5 \% 8 \mathrm{D} \% 94 \% \mathrm{E} 5 \% 9$ $0 \% 8 \mathrm{C} \% \mathrm{E} 8 \% \mathrm{~A} 8 \% \mathrm{AD} \% \mathrm{E} 8 \% \mathrm{~A} 8 \% 88+$ collaborative+design \&cd=9\&hl=z $\mathrm{h}-\mathrm{TW} \& \mathrm{ct}=\mathrm{clnk} \& \mathrm{gl}=\mathrm{tw}$

[32] Lee, H. -J. (2009). Teaching and learning for excellence-introduction and plan. Retrieved December 8, 2010, from http://www.tec.tcu.edu.tw/overview.aspx.

[33] Lee, I. -L. (2009). The impact of the mind mapping teaching plan on the visual art learning of sixth grade elementary school students exemplified by Chi Wen elementary school in Miao-Li county. Unpublished master thesis, National Hsinchu University of Education Fine art and crafts education, Hsinchu, Taiwan.

[34] Lin, R. -T. (2000). A study on the learning attitude of students of design department. Unpublished master thesis, National Taiwan University of Science and Technology, Graduate Institute of Applied Science and Technology, Taipei, Taiwan.

[35] Liu, K. -W., \& Hsieh, C. -C. (2009). The study of the effects of mind mapping program on the fifth-grade students' linguistic creativity in elementary school. STUT Journal of Humanities and Social Sciences, 1, 75-106.

[36] MindMapper Operation (2010). Mindmapper basics plus important features. Retrieved December 7, 2010, from http://www.mindmapperusa.com/features.htm

[37] Mind Mapping Software Helps Personal Development (2009). Computers and technology: Software. Retrieved December 7, 2010, from http://mind-map.com

[38] Ministry of Education (1999a). The $4^{\text {th }}$ annual first-session report of the Education Committee, Legislative Yuan. Retrieved September 16, 2008, from http://www.edu.tw/content.aspx?site_content_sn=546

[39] Ministry of Education (1999b). The $4^{\text {th }}$ annual second-session report of the Education Committee, Legislative Yuan. Retrieved September 16, 2008, from http://www.edu.tw/content.aspx?site_content_sn=580

[40] Ministry of Education (2000). The $4^{\text {th }}$ annual third-session report of the Education Committee, Legislative Yuan. Retrieved September 16, 2008, from http://www.edu.tw/content.aspx?site_content_sn=627 
[41] Ministry of Education (2005). The action plan for education policy implementation focus. Retrieved September 18, 2008, from http://www.edu.tw/content.aspx?site_content_sn=13535

[42] Novak, J. D., Gowin, D. B., \& Johansen, G. T. (1983). The use of concept mapping and knowledge via mapping with junior high school science students. Science Education, 67, 625-645.

[43] Paulus, P. B. (2000). Groups, teams, and creativity: The creative potential of idea-generating groups. applied psychology: An International Review, 49, 237-262.

[44] Phelan, A. (2006). Studio Art Education Today: the impact of Digital Media and Technology on the Pedagogical Structure. The International Journal of Arts Education, 4(1), 9-22.

[45] Schank, R. C., Berman, T. R., \& Macpherson, K. A. (1999). Learning by doing. In C. M. Reigeluth (Ed.), Instructional design theories and models. Mahwah, NJ: Erlbaum, 161-181.

[46] Scott, D. M. (2005). Thinking right about content. EContent, 28(6), 48.

[47] Shen, W., Hao, Q., \& Li, W. (2008). Computer supported collaborative design: Retrospective and perspective. Computers in Industry, 59, 855862.

[48] Sousa, D. A. (2003). How the gifted brain learns. Thousand Oaks, CA: Corwin.

[49] Sun, M. (2003). Mind map thinking method. Taipei: Radiant Mind Co., Ltd.

[50] Tang, H. -H., Lin, C. -W., \& Chen, W. -C. (2009). Exploring the relationship between personal creativity, creativity process, Concept Evolution, and Design Performance in a Collaborative Design Process. Journal of Design, 14(3), 51-71.

[51] Tidafi, T., \& Dorta, T. (Eds) (2009).Design tools and collaborative ideation. Tomás Dorta, Annemarie Lesage, Edgar Pérez Hybridlab, School Of Industrial Design, Université De Montréal, Canada. Retrieved December 7, 2010, from http://www.hybridlab.umontreal.ca/documents/23-CAADFutures.pdf

[52] Tseng, C. -F. (1987). A study of the development of the design learning. Design Education Proceeding, 130, 121-138.

[53] Tseng, Y. (2002). Divergent thinking detection and analysis for students of industrial design. Unpublished master thesis, National Chiao Tung University, Hsinchu, Taiwan
[54] Tung, Y. -J. (2005). The influence of communication modes among cross-functional research and development teams regarding design knowledge integration. Unpublished master thesis, Tatung University Graduate School of Industrial Design, Taipei, Taiwan.

[55] University Campus Suffolk (2010). BA (Hons) design. Retrieved December 7, 2010, from http://www.ucs.ac.uk/study/SchoolsAndCentres/Lowestoft/graphicsspec. aspx

[56] Wang, C. -W. (2003). Factors influencing teachers to involve in using web-based teaching platforms. Unpublished master thesis, Shu Te university institute of information management, Kaohsiung, Taiwan.

[57] Warr, A., \& O'Neill, E. (2005). Understanding design as a social creative process, Proceedings of the $5^{\text {th }}$ Conference on Creativity \& Cognition (pp. 629-642). London: ACM.

[58] Wavering, M. (1985). The logical reasoning necessary to make line graphs. Journal of Research in Science Teaching, 26, 373-379.

[59] Wu, M. -C. (2010). An analytic study of the effectiveness of thinking skills training courses of technical vocational high schools in enhancing students' problem solving abilities. Paper presented at the meeting of the 2009 Enhancement of Research Energy in National Science Council's Applied Science and Education and Result Presentation Seminar, Taipei, Taiwan.

[60] Wycoff, J. (1991). Mind mapping. New York: Berkley.

[61] Yang, L. -H. (1999). Distance learning curriculum in colleges and universities-the current situation and future developments. Unpublished master thesis, NTNU Institute of Industrial Technology Educational, Taipei, Taiwan.

[62] Yao, Y. -C. (2002). An exploration of critical success factors of the implementation of cyber university - A case study from "National Sun Yat-Sen cyber university". Unpublished master thesis, National Sun Yatsen University, Institute of Information Management, Kaohsiung, Taiwan.

[63] Yen, J., \& Hsu, C. -M. (2007). The functional designs of the web-based teaching platform for design field: An application of analytical hierarchy process. Journal of Science and Technology, 16(1), 61-80.

[64] You, M. -L., \& Chen, W. -Z. (2009). The problems and implications of online collaborative design learning projects. Research in Arts Education, 15, 105-137. 